\title{
Delirium in hospitalized patients with COVID-19 pneumonia: a prospective, cross-sectional, cohort study
}

\author{
Antonio Callea ${ }^{1}$ (1) $\cdot$ Giancarlo Conti $^{1} \cdot$ Barbara Fossati $^{1} \cdot$ Laura Carassale $^{2} \cdot$ Mariapia Zagaria $^{2} \cdot$ Silvia Caporotundo $^{2}$. \\ Eleonora Ziglioli ${ }^{2}$. Valerio Brunetti ${ }^{3,4}$. Giacomo Della Marca ${ }^{3,4}$. Eleonora Rollo ${ }^{4}$
}

Received: 7 October 2021 / Accepted: 15 January 2022 / Published online: 27 January 2022

(c) The Author(s), under exclusive licence to Società Italiana di Medicina Interna (SIMI) 2022

\begin{abstract}
Delirium is an acute confusional state characterized by altered level of consciousness and attention. Coronavirus Disease 2019 (COVID-19), caused by Severe Acute Respiratory Syndrome Coronavirus 2 (SARS-CoV-2), can manifest itself with this neuropsychiatric disorder. The endpoints of our study were: the frequency of delirium in subjects with COVID-19 pneumonia; the risk factors that predispose to this condition; and the impact of delirium on mortality. Subjects were consecutively enrolled in a Geriatric Unit from January 5th to March 5th, 2021. Inclusion criteria were: diagnosis of SARS-CoV-2 infection, a radiologically documented pneumonia, and the ability of providing informed consent. Exclusion criteria were: absence of radiological evidence of pneumonia, sepsis, and the need of intensive care unit treatment. All subjects were evaluated by means of Richmond Agitation Sedation Scale (RASS) and Confusion Assessment Method-Intensive Care Unit (CAM-ICU) at least twice per day. In the study cohort $(n=71)$, twenty patients $(28.2 \%)$ had delirium. Delirium was present on admission in $11.3 \%$, and occurred during hospitalization in $19.0 \%$. Compared to patients without delirium, patients who developed this neuropsychiatric disorder had a higher mortality rate (35\% vs 5.9\%) and an increased average hospital length of stay (21 days vs 17 days). In the multivariate analysis delirium was associated with frailty $(\mathrm{OR}=2.81 ; \mathrm{CI}=1.4-5.8)$ and helmet ventilation $(\mathrm{OR}=141.05 ; \mathrm{CI}=4.3-4663.9)$. Delirium was an independent predictor of mortality. Nearly a third of subjects $(28.2 \%)$ had delirium during hospitalization for COVID-19. This finding supports the notion that delirium is a common complication of SARS-CoV2 infection. Since delirium is associated with longer hospital stay, and it is an independent marker of increased mortality, clinicians should assess and prevent it.
\end{abstract}

Keywords COVID-19 $\cdot$ Delirium $\cdot$ Helmet-CPAP $\cdot$ Frailty $\cdot$ Comfortable care

Antonio Callea

antoniocalleamd@gmail.com

1 Department of Neurology, ASST Nord Milano, Ospedale Bassini, Via Massimo Gorki, 50, 20092 Milan, Cinisello Balsamo, Italy

2 Department of Geriatrics, ASST Nord Milano, Ospedale Bassini, Cinisello Balsamo, Milan, Italy

3 Dipartimento Scienze Dell'Invecchiamento, Neurologiche, Ortopediche E Della Testa-Collo, IRCCS Fondazione Policlinico Universitario A. Gemelli, Rome, Italy

4 Department of Neurosciences, Università Cattolica del Sacro Cuore, Rome, Italy

\section{Introduction}

Delirium is an acute confusional state characterized by altered level of consciousness and attention that develops over a short time and fluctuates in severity [1]. Based on motor behavior, delirium can be subdivided into 'hypoactive', 'hyperactive' and 'mixed' subtypes; the worst prognosis is associated with the hypoactive form which is also the most frequent [2]. Neuroinflammation, imbalance in neurotransmitters, and hypoxia are among the main pathophysiological mechanisms involved in the pathogenesis of delirium [3-5].

Coronavirus Disease 2019 (COVID-19), caused by Severe Acute Respiratory Syndrome Coronavirus 2 (SARS-CoV-2), was declared a pandemic on March 11, 2020, by the World Health Organization [6]. The most common clinical presentation of COVID-19 is a respiratory and/or gastrointestinal 
syndrome [7]. Atypical presentations have been described as well, including neuropsychiatric symptoms, such as headache, and disturbances of consciousness [8]. Delirium is a common initial manifestation of COVID-19, often without other typical symptoms or signs, as shown by a recent multicenter cohort study conducted in the setting of COVID19 Emergency Departments [9]. Moreover, delirium is a frequent complication of COVID-19 hospitalization and is associated with a worse prognosis, in terms of severity and mortality, as reported by recent studies [10-12]. At the beginning of the pandemic, delirium in COVID-19 has been mainly studied in intensive care units (ICU) where its prevalence has been estimated to be around 55\%; successively, an increasing number of studies assessed COVID-19-related delirium in non-ICU hospitalized patients, reporting a prevalence of $32.4 \%$ [13].

The primary objective of this study was to measure the frequency of delirium in older subjects hospitalized for COVID-19 related pneumonia. As a secondary aim, we investigated the clinical, therapeutic and laboratory variables associated with this neuropsychiatric disorder. Finally, we analyzed the impact of delirium on mortality.

\section{Materials and methods}

\section{Patients}

The study was performed according to a cross-sectional design. Subjects were consecutively enrolled among patients admitted to the Geriatric Unit of the Edoardo Bassini Hospital, Milan, Italy. The enrollment period went from January 5th to March 5th, 2021. Inclusion criteria were: diagnosis of SARS-CoV-2 infection, a radiologically documented pneumonia, and the ability of providing informed consent. Diagnosis of SARS-CoV-2 infection was confirmed after viral detection by reverse transcriptase polymerase chain reaction on nasal or throat swabs [14]. Pneumonia was suspected due to the presence of respiratory symptoms or fever and confirmed by chest $\mathrm{CT}$ imaging showing alveolar-interstitial damage with the typical peripheral ground-glass opacities [15] or by chest X-ray showing a multifocal and peripheral pattern, associated with interstitial and alveolar opacities [16]. Exclusion criteria were: absence of CT or X-ray typical lesions suggestive for pneumonia, extreme severity of clinical conditions requiring intubation and intensive care unit treatment, and presence of serum procalcitonin values higher than $10 \mathrm{ng} / \mathrm{ml}$, which were considered highly indicative of septic state. All subjects or caregivers gave written informed consent before enrollment. The study was performed in agreement with the Helsinki declaration, and was approved by the local Ethical Committee Milan Area 3.

\section{Clinical information collected}

For each subject, the following clinical data were recorded: sex, age, history of hypertension (systolic blood pressure $\geq 135 \mathrm{mmHg}$ and/or diastolic $\geq 85 \mathrm{mmHg}$ ), diabetes (fasting serum glucose $>127 \mathrm{mg} / \mathrm{dl}$ ), Chronic Obstructive Pulmonary Disease (COPD), cancer, myocardial infarction, chronic kidney disease, dementia, presence of atrial fibrillation (documented by Electrocardiogram, ECG), use of psychoactive drugs prior to hospitalization, use of antiviral therapy, use of dexamethasone, and type of ventilatory support used (non-helmet or helmet ventilation). Patients were assessed for frailty using the clinical frailty scale score (CFS), a validated tool which consists of clinical descriptors and nine pictographs [17]. In our analysis the variable "frailty" was dichotomized, according to a cut-off value of CFS $>5$ (CFS $\leq 5$ indicates mild frailty, CFS $>5$ indicates moderate to severe frailty).

On admission, also laboratory variables were assessed in order to establish their potential role as predictors of delirium. These variables included: $\mathrm{P}_{\mathrm{aO} 2}, \mathrm{P}_{\mathrm{a} 02} / \mathrm{F}_{\mathrm{iO} 2}$ ratio, $\mathrm{P}_{\mathrm{aCO} 2}$, and venous blood routine exams (hemoglobin, red blood cell count, lymphocyte count, platelet count, D-dimer, C-reactive Protein (CRP), procalcitonin (PCT), creatinine, alanine aminotransferase (ALT) and creatinephosphokinase (CPK)).

\section{Algorithm used to treat hypoxia and COVID-19}

Hypoxia treatment was initially based on the ratio of partial pressure arterial oxygen and fraction of inspired oxygen $\left(\mathrm{P}_{\mathrm{aO} 2} / \mathrm{F}_{\mathrm{iO} 2}\right)$ on room air, and respiratory rate using a practical algorithm [18]. Patients with oxygen saturation measured by pulse oximetry $<95 \%$ or $\mathrm{P}_{\mathrm{a} 02} / \mathrm{F}_{\mathrm{iO} 2}>200$ received oxygen through oxygen mask with or without reservoir. Continuous Positive Airway Pressure (CPAP) criteria were $\mathrm{P}_{\mathrm{aO} 2} / \mathrm{F}_{\mathrm{iO} 2}<200, \mathrm{P}_{\mathrm{aO} 2}<60 \mathrm{mmHg}$, and respiratory rate $>30 /$ minute. CPAP, when indicated, was delivered through high-flow generator using a helmet (H-CPAP) as interface with a PEEP valve (StarMed, Italy). CPAP was started at $10 \mathrm{cmH}_{2} \mathrm{O}$ in all patients, and $\mathrm{F}_{\mathrm{iO} 2}$ was set to $40-60 \%$ to achieve $\mathrm{P}_{\mathrm{aO} 2} \geq 60 \mathrm{mmHg}$. To reduce the noise inside the helmet, generated by the gas flow, a Heat and Moisture Exchanger (HME) filter on the helmet gas inspiratory limb was employed. The counterweights system was used to anchor the helmet during H-CPAP to reduce patient discomfort; patients were put in a semisupine or sitting position. Patients on H-CPAP who did not show signs of respiratory distress and maintained a $\mathrm{SpO}_{2}>94 \%$ with a $\mathrm{F}_{\mathrm{iO} 2}<50 \%$ and a PEEP $\leq 5 \mathrm{cmH}_{2} \mathrm{O}$ underwent a weaning trial. Weaning was started when no 
desaturation or tachypnea appeared during H-CPAP interruptions for eating, with $\mathrm{P}_{\mathrm{a} 02} / \mathrm{F}_{\mathrm{iO} 2}>250$. The interruptions were then progressively lengthened and patients maintaining a $\mathrm{P}_{\mathrm{a} 02} / \mathrm{F}_{\mathrm{iO} 2}>250$ on oxygen mask without reservoir for at least $24 \mathrm{~h}$ were considered successfully weaned from H-CPAP. High flow oxygen was not used as a treatment in our protocol.

Patients were eligible for remdesivir if oxygen saturation was $94 \%$ or less, while they were breathing ambient air or were receiving supplemental oxygen. Exclusion criteria for antiviral therapy included mechanical ventilation, interval from symptom onset $>9$ days, transaminases levels greater than 5 times the upper limit of the normal range, and estimated creatinine clearance $<50 \mathrm{ml} / \mathrm{min}$ [19]. Dexamethasone $6 \mathrm{mg}$ once daily IV for up to 10 days was prescribed to those who were receiving either H-CPAP or oxygen alone [20].

\section{Delirium assessment}

Delirium was assessed by two physicians of the hospital ward (AC, LC), who visited the subjects at least twice per day, using the Confusion Assessment Method-Intensive Care Unit (CAM-ICU). CAM-ICU is an adaptation of the Confusion Assessment Method (CAM) score for use in ICU [21]. If the CAM-ICU was positive, subjects were further evaluated by a neurologist (AC) using the DSM-V criteria to confirm the diagnosis of delirium [1].The Richmond Agitation Sedation Scale (RASS) was used to classify delirium into hyperactive, hypoactive and mixed subtypes [22].

Regardless of the two daily assessments, subjects were screened at any time in case of development of fluctuation in mental status, altered consciousness, fluctuating attention, or disorganized thinking.

\section{Statistical analysis}

In text and tables, numerical variables are presented as median followed by interquartile range (IQR), categorical variables as number (n) followed by percentage (\%). The distribution of all the study variables was tested for normality with the Shapiro-Wilk test.

The study population was divided into two subgroups: patients with delirium $(\mathrm{DLR}+)$ and patients without delirium (DLR-). In the univariate analysis, all variables were compared between the subgroups DLR + vs DLR-. Due to non-normal distribution, non-parametric tests were adopted: the Mann-Whitney $U$-test was used to compare numerical variables, and the Pearson's chi-square $\left(\chi^{2}\right)$ for the categorical variables. The level of significance was set at $p<0.05$.

Successively, to adjust the effect size for potential confounders, a multivariate analysis was performed, with delirium (condition DLR + ) as the dependent variable. Variables used in the univariate analysis were entered into a multivariate logistic regression analysis to determine adjusted odds ratios. The multivariate model was built choosing variables for the significance in the univariate comparison and for clinical relevance [23]. The goodness of fit for the logistic regression model was evaluated with the Hosmer-Lemeshow test and the Nagelkerke $\mathrm{R}_{2}$.

As further analysis, we evaluated the impact of delirium on mortality, using a logistic regression analysis in which death was the dependent variable, and age, and frailty were assessed as possible confounders.

All statistics were performed by means of the Statistical Package for Social Science (SPSS $®$ ) software version 22 (SPSS, Inc., Chicago, IL, USA).

\section{Results}

During the study period, 111 subjects were admitted to Geriatric Unit and screened for enrollment (Fig. 1). Forty subjects were excluded because they did not fulfill the inclusion and exclusion criteria; finally, 71 subjects were enrolled, 41 men (57.7\%) and 30 women (42.3\%); median age was 77 (IQR: 68-82). The main demographic and clinical features of the study population are summarized in Table 1.

Delirium was diagnosed in 20 subjects (28.2\%); among these, the 'hypoactive' type was observed in 10 cases (50\%), the 'hyperactive' in 4 cases (20\%), 6 subjects had 'mixedtype' delirium (30\%). Symptoms of delirium were present at hospital admission in 8/71 patients (11.3\%); of the remaining 63 patients, 12 developed delirium during hospitalization (19.0\%). In patients who developed delirium during hospitalization, delirium occurred after a mean of 3.5 days after hospital admission.

All the numerical variables showed a non-normal distribution, thus univariate comparisons were made with non-parametrical tests. Subjects with delirium were older (DLR + : 81 vs DLR-: 74 years; $U$-test $=723.0$, $p=<0.001)$ and showed higher frailty index (DLR $+: 6$ vs DLR-: 3 ; $U$-test $=833.0, p<0.001)$. Significant differences between the two groups were observed in high grade of frailty, defined as CFS > 5, (DLR + : 15/20 vs DLR-: 5/51; $\chi^{2}=30.527, p<0.01$ ), helmet ventilation (DLR $+: 9 / 20 \mathrm{vs}$ DLR-: $9 / 51 ; \chi^{2}=6.999, p=0.03$ ), dementia (DLR $+: 9 / 20$ vs DLR-: $\left.4 / 51 ; \chi^{2}=12.933, p<0.001\right)$, use of psychoactive drugs (DLR + : 10/20 vs DLR-: 6/51; $\chi^{2}=11.699$, $p=0.001$ ), previous stroke (DLR $+: 7 / 20$ vs DLR-: $6 / 51$; $\chi^{2}=4.997, p=0.025$ ), and neoplastic diseases (DLR + : 6/20 vs DLR-: $\left.5 / 51 ; \chi^{2}=4.314, p=0.04\right)$. As concerns the impact of delirium on outcome measures, patients with delirium had longer hospitalization, though not significantly (DLR +: 21 days vs DLR-: 17 days), and showed higher mortality rate (DLR $+: 7 / 20$ vs DLR-: $3 / 51 ; \chi^{2}=10.066$, 
Fig. 1 Flow chart of the study. $P C T$ procalcitonin

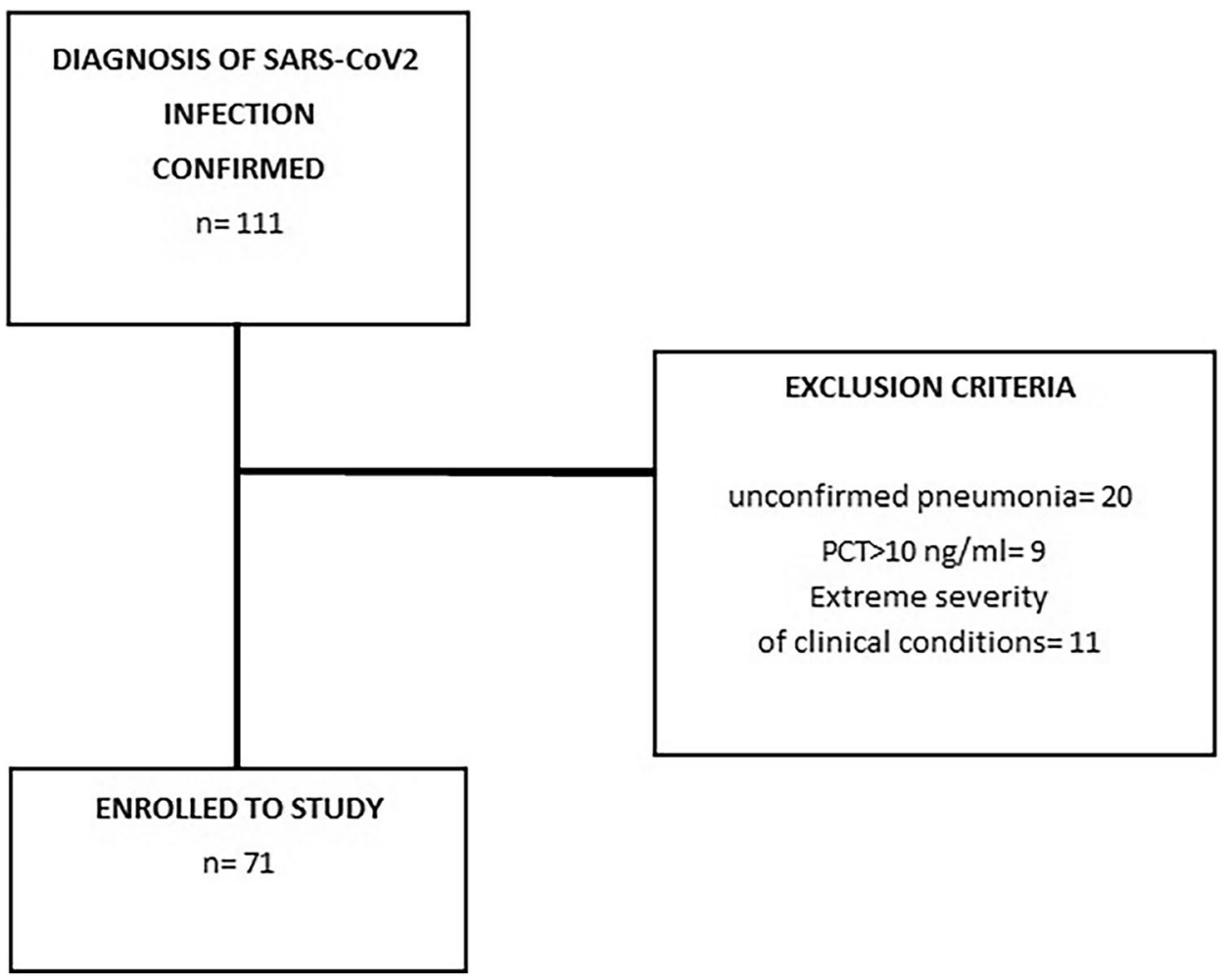

$p<0.01)$. No significant difference was observed in the other clinical parameters considered. Results of the univariate comparison are shown in Table 1.

In the multivariate analysis, delirium (condition DLR +) was significantly associated with frailty $(\mathrm{OR}=2.81$; $\mathrm{CI}=1.4-5.7)$, and with helmet ventilation $(\mathrm{OR}=141.05$; $\mathrm{CI}=4.3-4663.9)$. No variable was significantly associated with the DLR- condition. The Hosmer-Lemeshow test was not significant ( $p=0.939$ ); Nagelkerke $R_{2}$ was 0.782 . Detailed results of the multivariate analysis are displayed in Table 2, forest plot is in Fig. 2.

Among the factors associated with outcome in our population, mortality, after correction for frailty and age, was significantly associated with delirium (OR 7.094, CI 1.020-49.384). Results of this multivariate analysis of mortality are shown in Table 3.

\section{Discussion}

The primary endpoint of our study was the incidence of delirium in subjects with COVID-19-related pneumonia admitted to a noncritical care unit.

Overall, 20/71 patients (28.2\%) had delirium; of these, eight $(11.3 \%)$ showed delirium upon admission and 12 (19.0\%) developed delirium during hospitalization. This finding supports the evidence that delirium is a common complication of SARS-CoV-2 infection. The frequencies of delirium, in our cohort, are slightly lower than those reported in a recent systematic review assessing delirium in COVID19 patients aged over 65 years $(28.2 \%$ upon admission and $25.2 \%$ during hospitalization) [13]. This discrepancy could be explained by the fact that the majority of our patients were screened for delirium after an average time of 7 days from the COVID-19 symptoms onset. In our cohort, hypoactive delirium was the predominant motor subtype (50\%), followed by mixed delirium $(30 \%)$ and hyperactive delirium $(20 \%)$. Our findings are in line with previous reports concerning the prevalence of the different motor subtypes of delirium [2].

The secondary endpoint of our study was the identification of factors associated with delirium onset. Delirium is rarely caused by a single factor; rather, it represents a multifactorial syndrome caused by a complex interrelationship between predisposing factors ("baseline admission patient vulnerability") and precipitating factors ("insults") occurring during hospitalization [24]. In our study, predisposing factors associated with delirium occurrence were older age, dementia, use of psychoactive drugs prior to hospital admission, previous stroke, and history of cancer. Delirium was independently associated with frailty. Frailty is a geriatric condition characterized by increased vulnerability for adverse events. Many studies have demonstrated that frailty increases the risk of delirium underscoring the need for early screening of frailty in hospitalized patients [25-27]. The reason for this increased susceptibility is likely related to 
Table 1 Demographic, laboratory, and clinical characteristics of the study cohort, and univariate comparison between the DLR + vs DLRgroups

\begin{tabular}{|c|c|c|c|c|c|c|c|}
\hline & \multicolumn{2}{|c|}{ STUDY COHORT $(n=71)$} & \multicolumn{2}{|l|}{$\mathrm{DLR}+(n=20)$} & \multicolumn{2}{|l|}{ DLR- $(n=51)$} & \multirow[t]{2}{*}{$p$} \\
\hline & Median (IQR) & $n(\%)$ & Median (IQR) & $n(\%)$ & Median (IQR) & $n(\%)$ & \\
\hline \multicolumn{8}{|l|}{ Demographics } \\
\hline Sex & & $41(57.7)$ & & $11(55)$ & & $30(58.8)$ & 0.77 \\
\hline Age & $77(68-82)$ & & $81(75-86)$ & & $74(64-82)$ & & $<0.01$ \\
\hline Frailty & $3(2-5)$ & & $6(5-7)$ & & $3(1-3)$ & & $<0.01$ \\
\hline Death & & $10(14.1)$ & & $7(35)$ & & $3(5.9)$ & $<0.01$ \\
\hline \multicolumn{8}{|l|}{ Laboratory variables (n.r) } \\
\hline $\mathrm{PaO} 2(\mathrm{mmHg})$ & $62(53-73)$ & & $61(53-68)$ & & $64(55-74)$ & & 0.44 \\
\hline $\mathrm{PaO} 2 / \mathrm{FiO} 2$ & $281(196-343)$ & & 267 (219-299) & & $286(154-343)$ & & 0.63 \\
\hline $\mathrm{PaCO} 2(\mathrm{mmHg})$ & $31(29-35)$ & & $31(29-36)$ & & $32(29-35)$ & & 0.90 \\
\hline D-dimer $(\mu \mathrm{g} / \mathrm{l})$ & 765 (517-1437) & & $1079(565-1800)$ & & $753(517-1382)$ & & 0.47 \\
\hline $\mathrm{Hb}(\mathrm{g} / \mathrm{dl})$ & $14.15(12.9-15.2)$ & & $13.55(12.4-15.3)$ & & $14.25(13.0-15.0)$ & & 0.64 \\
\hline Red cells $\left(n \times 10^{12} / 1\right)$ & $4.66(4.25-5.07)$ & & $4.67(4.31-5.05)$ & & $4.66(4.22-5.00)$ & & 0.90 \\
\hline Platelets $\left(n \times 10^{9} / 1\right)$ & $221(152-273)$ & & $216.5(150.3-263.3)$ & & $221(156-292)$ & & 0.58 \\
\hline Lymphocytes $\left(n \times 10^{9} / 1\right)$ & $0.91(0.67-1.20)$ & & $0.875(0.60-1.10)$ & & $0.92(0.71-1.00)$ & & 0.25 \\
\hline Creatinine (mg/dl) & $0.92(0.80-1.25)$ & & $1,04(0.78-1.35)$ & & $0.92(0.81-1)$ & & 0.63 \\
\hline $\operatorname{ALT}(\mathrm{UI} / \mathrm{l})$ & $29(18-39)$ & & $29(18-42)$ & & $28(19-39)$ & & 0.68 \\
\hline CK (UI/l) & $105(63-201)$ & & $107(69-228)$ & & $100(61-198)$ & & 0.53 \\
\hline $\mathrm{CRP}(\mathrm{mg} / \mathrm{dl})$ & $6.6(2.5-13.8)$ & & $7.15(3.1-13.8)$ & & $6.46(2.3-12.0)$ & & 0.71 \\
\hline PCT (ng/ml) & $0.7(0.4-1.1)$ & & $0.9(0.7-1.6)$ & & $0.6(0.4-1.0)$ & & 0.06 \\
\hline \multicolumn{8}{|l|}{ Comorbidities } \\
\hline Dementia & & $13(18.3)$ & & $9(45)$ & & $4(7.8)$ & $<0.01$ \\
\hline Previous Stroke & & $13(18.3)$ & & $7(35)$ & & $6(11.8)$ & 0.03 \\
\hline COPD & & $12(16.9)$ & & $3(15)$ & & $9(17.6)$ & 0.76 \\
\hline CKD & & $8(11.3)$ & & $4(20)$ & & $4(7.8)$ & 0.16 \\
\hline Diabetes & & $21(29.6)$ & & $7(35)$ & & $14(27.5)$ & 0.60 \\
\hline Myocardial infarction & & $15(21.1)$ & & $5(25)$ & & $10(19.6)$ & 0.65 \\
\hline Atrial Fibrillation & & $14(19.7)$ & & $5(25)$ & & $9(17.6)$ & 0.51 \\
\hline Hypertension & & $37(52.1)$ & & $12(60)$ & & $25(49.0)$ & 0.50 \\
\hline Cancer & & $11(15.5)$ & & $6(30)$ & & $5(9.8)$ & 0.04 \\
\hline \multicolumn{8}{|l|}{ Treatments } \\
\hline H-CPAP & & $18(25.4)$ & & $9(45)$ & & $9(17.6)$ & $\mathbf{0 . 0 3}$ \\
\hline Dexamethasone & & $69(97.2)$ & & $20(100)$ & & $49(96.1)$ & 0.37 \\
\hline Remdesivir & & $18(25.4)$ & & $6(30)$ & & $12(23.5)$ & 0.50 \\
\hline Enoxaparin & & $59(83.1)$ & & $18(90)$ & & $41(80.4)$ & 0.19 \\
\hline Psychoactive drugs & & $16(22.5)$ & & $10(50)$ & & $6(11.8)$ & $<0.01$ \\
\hline
\end{tabular}

$A L T$ aspartate alanine transaminase, $C P K$ creatine-kinase, $C R P$ C-reactive protein, $P C T$ procalcitonin, $A F$ atrial fibrillation, $C O P D$ chronic obstructive pulmonary disease, $C K D$ chronic kidney disease, $H$-CPAP helmet-continuous positive airway pressure

the pathophysiological link between frailty and delirium. In 2017 Maldonado introduced the concept of "systems integration failure hypothesis" underlining that inflammation, oxidative stress, neuroendocrine dysregulation and circadian dysregulation were all delirium substrates [28]. All of the cited substrates are also implicated in the pathophysiology of Frailty Syndrome. Our study showed that moderate or severe frailty characterizes the subgroup of patients with higher risk of delirium. Considering that subjects with CFS $>5$ are often affected by moderate/severe grade of disability, our study indirectly suggests that also disability may be a predisposing factor for delirium development [29].

Regarding precipitating factors, we found that helmet ventilation was associated with delirium occurrence. The role of helmet ventilation for delirium development was confirmed also after adjustment for potentially confounding factors (Fig. 2; Table 2). Eighteen out of 71 patients required H-CPAP during hospitalization, and nine of them 
Table 2 Multivariate logistic regression analysis with delirium as dependent variable

\begin{tabular}{|c|c|c|c|c|}
\hline & \multicolumn{4}{|c|}{ Dependent variable: Delirium } \\
\hline & $p$ & OR & CI (lower) & CI (upper) \\
\hline Age & 0.315 & 1.087 & 0.923 & 1.280 \\
\hline Frailty & $<0.01$ & 2.812 & 1.374 & 5.755 \\
\hline Dementia & 0.847 & 1.307 & 0.087 & 19.679 \\
\hline Psychoactive drugs & 0.052 & 19.538 & 0.976 & 391.017 \\
\hline Previous stroke & 0.443 & 2.521 & 0.238 & 26.737 \\
\hline Neoplastic diseases & 0.708 & 0.565 & 0.028 & 11.286 \\
\hline H-CPAP & 0.021 & 141.056 & 4.266 & 4663.959 \\
\hline
\end{tabular}

$O R$ odds ratio, $H$-CPAP helmet-CPAP

(50\%) developed delirium. Only in one case, delirium development was prior to helmet application, while in the remaining cases delirium occurred after an average of 1.3 days from H-CPAP application. As mentioned in the methods, $\mathrm{H}-\mathrm{CPAP}$ was applied in the case of worsening of respiratory exchanges documented by $\mathrm{P}_{\mathrm{a} 02} / \mathrm{F}_{\mathrm{iO} 2}$ and $\mathrm{P}_{\mathrm{a} 02}$ values. It is worth to underline that patients who received $\mathrm{H}$-CPAP suffered from severe hypoxemia [5, 30]. H-CPAP, an alternative way to deliver continuous positive airway pressure without aerosolization in the environment, is an effective treatment of COVID-19 respiratory failure [31]. Compared to facial mask CPAP, the use of a helmet has the advantage of
Table 3 Multivariate (logistic regression) analysis; dependent variable: Death

\begin{tabular}{llllc}
\hline & \multicolumn{4}{l}{ Dependent variable: Death } \\
\cline { 2 - 5 } & & OR & CI (lower) & CI (upper) \\
\hline Age & 0.401 & 1.030 & 0.951 & 1.133 \\
Frailty & 0.905 & 0.973 & 0.619 & 1.529 \\
Delirium & 0.048 & 7.094 & 1.020 & 49.384 \\
\hline
\end{tabular}

$O R$ odds ratio

reducing aerosolization and exposure to SARS-CoV-2 [32], occurrence of skin lesions [33] and gastric distension [34]. However, use of the helmet is not free from disadvantages, including noise, armpits pain, and possible claustrophobia. The helmet use is associated with significantly greater noise than nasal or facial masks and long-term exposure to loud noise may increase the subject's discomfort [35]. In addition to these sources of discomfort, it is reasonable to underline that subjects with H-CPAP have extreme limitations of movements and therefore resistance may be encountered when the subject is asked to switch to prone position. Movement limitation is a known precipitating factor for delirium development as shown by recent works addressing that physical restraint and prohibited self-transfer may favor

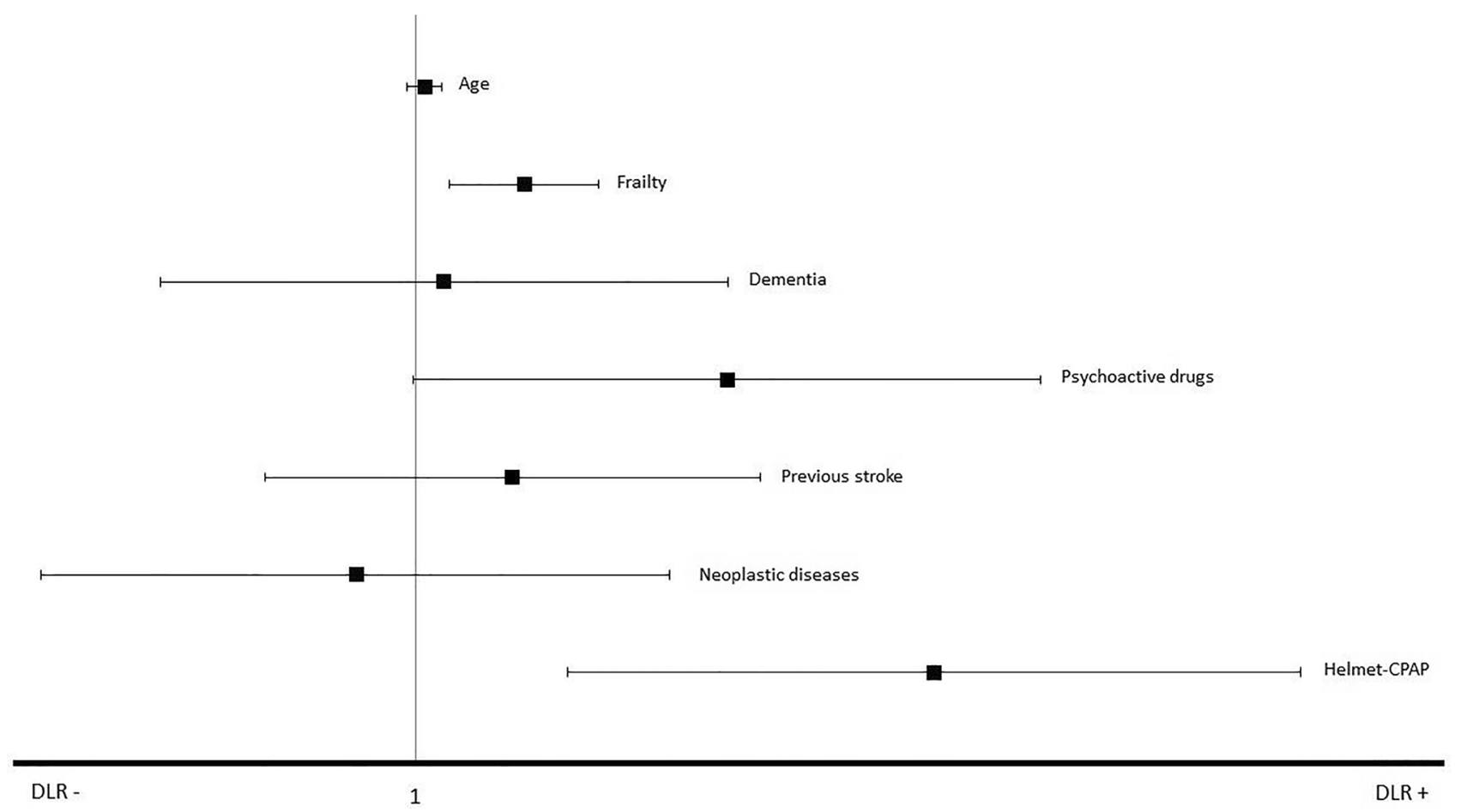

Fig. 2 Results of multivariate logistic regression analysis. Confidence intervals are represented in logarithmic scale. $D L R+$ patients with delirium, $D L R$ - patients without delirium 
delirium occurrence [36-39]. Overall, our study suggests that the patient's discomfort may play a role in favoring the onset of delirium.

Finally, our study confirms the notion that delirium is associated with a worse prognosis also in patients with COVID-19 pneumonia, as demonstrated by increased mortality in the subgroup of patients with delirium.

The current study presents some limitations. The most relevant limits are represented by the relatively low number of cases, and the impossibility of a blinded assessment of delirium. On the other hand, the main strength is the adoption of a prospective enrollment. Indeed, the majority of published studies chose a retrospective design, probably due to the difficulties in collecting data from COVID-19-hospitalized patients, such as protective equipment limitations to effective doctor-patient communication [40], or high level of working stress [41].

To conclude, our study confirms that delirium is a common issue in older and frail patients hospitalized for COVID-19 pneumonia, that it can be triggered by uncomfortable care, and that it is associated with a worse outcome.

Funding This research received no specific grant from any funding agency in the public, commercial, or not-for-profit sectors.

\section{Declarations}

Conflict of interest On behalf of all authors, the corresponding author states that there is no conflict of interest.

Ethical approval Ethical approval for this study was obtained from the local Ethical Committee Milan Area 3.

Informed consent All participants gave written informed consent before enrollment.

Disclosures All authors report no disclosure.

\section{References}

1. Association AP (2013) Diagnostic and statistical manual of mental disorders (DSM-5®)

2. Potter J, George J, G Guideline Development (2006) The prevention, diagnosis and management of delirium in older people: concise guidelines. Clin Med (Lond) 6:303-308

3. Cunningham C, Maclullich AM (2013) At the extreme end of the psychoneuroimmunological spectrum: delirium as a maladaptive sickness behaviour response. Brain Behav Immun 28:1-13

4. Hshieh TT, Fong TG, Marcantonio ER, Inouye SK (2008) Cholinergic deficiency hypothesis in delirium: a synthesis of current evidence. J Gerontol A Biol Sci Med Sci 63:764-772

5. Cerebral O, Neurological outcomes following critical illness research G, Canadian Critical Care Trials G et al (2017) Low brain tissue oxygenation contributes to the development of delirium in critically ill patients: A prospective observational study. J Crit Care 41:289-295
6. Cucinotta D, Vanelli M (2020) WHO declares COVID-19 a pandemic. Acta Biomed 91:157-160

7. Huang C, Wang Y, Li X et al (2020) Clinical features of patients infected with 2019 novel coronavirus in Wuhan, China. Lancet 395:497-506

8. Mao L, Jin H, Wang M et al (2020) Neurologic manifestations of hospitalized patients with coronavirus disease 2019 in Wuhan, China. JAMA Neurol 77:683-690

9. Kennedy M, Helfand BKI, Gou RY et al (2020) Delirium in older patients with COVID-19 presenting to the emergency department. JAMA Netw Open 3:e2029540

10. Ticinesi A, Cerundolo N, Parise A et al (2020) Delirium in COVID-19: epidemiology and clinical correlations in a large group of patients admitted to an academic hospital. Aging Clin Exp Res 32:2159-2166

11. Marengoni A, Zucchelli A, Grande G, Fratiglioni L, Rizzuto D (2020) The impact of delirium on outcomes for older adults hospitalised with COVID-19. Age Ageing 49:923-926

12. Watne LO, Tonby K, Holten AR et al (2021) Delirium is common in patients hospitalized with COVID-19. Intern Emerg Med https://doi.org/10.1007/s11739-021-02715-x

13. Shao SC, Lai CC, Chen YH et al (2021) Prevalence, incidence and mortality of delirium in patients with COVID-19: A systematic review and meta-analysis. Age Ageing. https://doi.org/ 10.1093/ageing/afab103.

14. Sethuraman N, Jeremiah SS, Ryo A (2020) Interpreting Diagnostic Tests for SARS-CoV-2. JAMA 323:2249-2251

15. Caruso D, Zerunian M, Polici M et al (2020) Chest CT features of COVID-19 in Rome, Italy. Radiology 296:E79-E85

16. Ippolito D, Maino C, Pecorelli A et al (2020) Chest X-ray features of SARS-CoV-2 in the emergency department: a multicenter experience from northern Italian hospitals. Respir Med 170:106036

17. Juma S, Taabazuing MM, Montero-Odasso M (2016) Clinical frailty scale in an acute medicine unit: a simple tool that predicts length of stay. Can Geriatr J 19:34-39

18. Brusasco C, Corradi F, Di Domenico A et al (2021) Continuous positive airway pressure in COVID-19 patients with moderateto-severe respiratory failure. Eur Respir J https://doi.org/10. 1183/13993003.02524-2020.

19. Beigel JH, Tomashek KM, Dodd LE (2020) Remdesivir for the treatment of Covid-19 - preliminary report. Reply N Engl J Med 383:994

20. Group RC, Horby P, Lim WS et al (2021) Dexamethasone in hospitalized patients with Covid-19. N Engl J Med 384:693-704

21. Ely EW, Inouye SK, Bernard GR et al (2001) Delirium in mechanically ventilated patients: validity and reliability of the confusion assessment method for the intensive care unit (CAMICU). JAMA 286:2703-2710

22. Sessler CN, Gosnell MS, Grap MJ et al (2002) The Richmond agitation-sedation scale: validity and reliability in adult intensive care unit patients. Am J Respir Crit Care Med 166:1338-1344

23. Bursac Z, Gauss CH, Williams DK, Hosmer DW (2008) Purposeful selection of variables in logistic regression. Source Code Biol Med 3:17

24. Inouye SK, Charpentier PA (1996) Precipitating factors for delirium in hospitalized elderly persons. Predictive model and interrelationship with baseline vulnerability. JAMA 275:852-857

25. Geriatric Medicine Research C (2019) Delirium is prevalent in older hospital inpatients and associated with adverse outcomes: results of a prospective multi-centre study on World Delirium Awareness Day. BMC Med 17:229

26. Zhang XM, Jiao J, Xie XH, Wu XJ (2021) The association between frailty and delirium among hospitalized patients: an updated meta-analysis. J Am Med Dir Assoc 22:527-534 
27. Mazzola P, Tassistro E, Di Santo S et al (2021) The relationship between frailty and delirium: insights from the 2017 Delirium Day study. Age Ageing 50:1593-1599

28. Maldonado JR (2017) Acute brain failure: pathophysiology, diagnosis, management, and sequelae of delirium. Crit Care Clin 33:461-519

29. Bellelli G, Morandi A, Di Santo SG et al (2016) "Delirium Day": a nationwide point prevalence study of delirium in older hospitalized patients using an easy standardized diagnostic tool. BMC Med 14:106

30. Lin Y, Chen Q, Zhang H et al (2020) Risk factors for postoperative delirium in patients with triple-branched stent graft implantation. J Cardiothorac Surg 15:171

31. Grieco DL, Menga LS, Cesarano M et al (2021) Effect of helmet noninvasive ventilation vs high-flow nasal oxygen on days free of respiratory support in patients with COVID-19 and moderate to severe hypoxemic respiratory failure: The HENIVOT Randomized clinical trail. JAMA. https://doi.org/10.1001/jama.2021.4682

32. Cabrini L, Landoni G, Zangrillo A (2020) Minimise nosocomial spread of 2019-nCoV when treating acute respiratory failure. Lancet 395:685

33. Bambi S, Peris A, Esquinas AM (2016) Pressure Ulcers Caused by Masks During Noninvasive Ventilation. Am J Crit Care 25:6

34. Antonelli M, Conti G, Pelosi P et al (2002) New treatment of acute hypoxemic respiratory failure: noninvasive pressure support ventilation delivered by helmet-a pilot controlled trial. Crit Care Med 30:602-608
35. Cavaliere F, Conti G, Costa R et al (2004) Noise exposure during noninvasive ventilation with a helmet, a nasal mask, and a facial mask. Intensive Care Med 30:1755-1760

36. Nakamizo T, Kanda T, Kudo Y et al (2021) Effects of uncomfortable care and histamine $\mathrm{H} 2$-antagonists on delirium in acute stroke: A propensity score analysis. J Neurol Sci 420:117251

37. Rollo E, Callea A, Brunetti V et al (2021) Delirium in acute stroke: A prospective, cross-sectional, cohort study. Eur J Neurol https://doi.org/10.1111/ene.14749

38. Nakamizo T, Kanda T, Kudo Y et al (2020) Development of a clinical score, PANDA, to predict delirium in stroke care unit. J Neurol Sci 415:116956

39. Rollo E, Callea A, Brunetti V et al (2021) Physical restraint precipitates delirium in stroke patients. J Neurol Sci 421:117290

40. Samarasekara K (2020) 'Masking' emotions: doctor-patient communication in the era of COVID-19. Postgrad Med J https://doi. org/10.1136/postgradmedj-2020-138444

41. Salari N, Khazaie H, Hosseinian-Far A et al (2020) The prevalence of stress, anxiety and depression within front-line healthcare workers caring for COVID-19 patients: a systematic review and meta-regression. Hum Resour Health 18:100

Publisher's Note Springer Nature remains neutral with regard to jurisdictional claims in published maps and institutional affiliations. 